\title{
Surgicel ${ }^{\circledR}$ granuloma mimicking ovarian cancer: A case report
}

\author{
LUIGI CORMIO ${ }^{1}$, GENNARO CORMIO ${ }^{2,3}$, GIUSEPPE DI FINO ${ }^{1}$, CARMEN SCAVONE ${ }^{4}$, \\ FRANCESCA SANGUEDOLCE $^{5}$, VERA LOIZZI ${ }^{2,3}$ and GIUSEPPE CARRIERI ${ }^{1}$ \\ ${ }^{1}$ Department of Urology and Renal Transplantation, University of Foggia, I-71100 Foggia; ${ }^{2}$ Department of \\ Biomedical Science and Human Oncology, Obstetrics and Gynecology Unit, University of Bari, I-70121 Bari; \\ ${ }^{3}$ Gynecologic Oncology Unit, National Institute for Research and Treatment 'Giovanni Paolo II', I-70124 Bari; \\ Departments of ${ }^{4}$ Radiology and ${ }^{5}$ Pathology, University of Foggia, I-71100 Foggia, Italy
}

Received February 3, 2015; Accepted January 4, 2016

DOI: $10.3892 / 01.2016 .4689$

\begin{abstract}
Surgicel ${ }^{\circledR}$ is an absorbable sterile mesh composed of oxidized cellulose that is used to control intraoperative capillary or venous bleeding, due to its capacity to bind hemoglobin, thus allowing the formation of an artificial clot. In the present study, a large granuloma mimicking ovarian cancer, which developed following placement of a Surgicel ${ }^{\circledR}$ sponge during a combined pubovaginal sling procedure and cystocele repair, is reported. The aim of the present case report is to emphasize the fact that hemostatic measures should be removed following their use, and to alert surgeons to the risk of using and leaving in situ oxidized cellulose. Furthermore, accurate evaluation of the surgical history of the patient should always be performed prior to attempting surgery.
\end{abstract}

\section{Introduction}

Surgicel ${ }^{\circledR}$ (Johnson \& Johnson Medical Ltd., Wokingham, $\mathrm{UK}$ ) is an absorbable sterile mesh composed of oxidized cellulose, which is used to control intraoperative capillary or venous bleeding (1). Surgicel ${ }^{\circledR}$ binds hemoglobin, allowing the formation of an artificial clot (2). Although the manufacturer recommends its removal following achievement of hemostasis, Surgice ${ }^{\circledR}$ is frequently left in situ to reabsorb spontaneously, typically with no untoward effects (3).

Adverse reactions to Surgice ${ }^{\circledR}$ include burning, stinging sensation or, more rarely, a foreign body reaction $(4,5)$. It has been reported that $40 \%$ of foreign body reactions are diagnosed within the initial year subsequent to surgery, and $50 \%$ are discovered $\geq 5$ years following surgery (6-8). The majority of these complications occur outside the abdominal cavity, and

Correspondence to: Professor Vera Loizzi, Department of Biomedical Science and Human Oncology, Obstetrics and Gynecology Unit, University of Bari, 11 Piazza Giulio Cesare, I-70121 Bari, Italy

E-mail:vloizzi@tiscali.it; vera.loizzi@uniba.it

Key words: Surgicel ${ }^{\circledR}$, ovarian cancer, granuloma a limited number of cases of Surgicel ${ }^{\circledR}$-associated granuloma linked to gynecological surgery have been reported thus far (6-8).

The present study reports a case of Surgicel ${ }^{\circledR}$-associated granuloma mimicking ovarian cancer following a combined pubovaginal sling procedure and cystocele repair, and reviews the literature concerning this rare pathological condition. Written informed consent was obtained from the patient.

\section{Case report}

In June 2012, a 67-year-old Caucasian woman underwent a combined pubovaginal sling procedure and cystocele repair at the Department of Urology and Renal Transplantation, University of Foggia (Foggia, Italy), using a large graft of autologous rectus muscle fascia, for the treatment of anterior genital prolapse with urinary stress incontinence. A Surgice ${ }^{\circledR}$ bolster purchased from Johnson \& Johnson Medical Ltd., was placed in each perivesical space to achieve hemostasis. The postoperative course was uneventful. At six-month follow-up, the patient complained of irritative voiding symptoms, which had progressively increased over the previous month. Urine culture was negative. Pelvic and transvaginal ultrasound revealed an 89-mm cystic lesion, with a 37-mm hyperechoic area on its wall, located in the right perivesical space (Fig. 1). Magnetic resonance imaging (MRI) confirmed the presence of a cystic lesion with a thick solid inner area (Fig. 2). The cystic walls presented intense contrast enhancement, whereas the solid area did not exhibit any increase in signal following administration of gadolinium (MultiHance ${ }^{\circledR}$, Bracco Diagnostics Inc., Monroe Township, NJ, USA). There was no sign of bladder or rectal invasion and no apparent lymph node involvement. The level of CA125 serum tumor marker was $10 \mathrm{U} / \mathrm{ml}$, which was within the normal range $(<35 \mathrm{U} / \mathrm{ml})$. Transperitoneal laparoscopic exploration revealed a large extraperitoneal mass arising from the right perivesical space and compressing the right ovary, which was normal in appearance. The mass was excised, and was observed to contain dark-brown particulate matter. Pathological examination revealed the presence of a large plasma cellular and granulocytic reaction, suggesting the occurrence of a foreign body reaction around the cellulose fibers (data not shown). Diagnosis of a Surgicel ${ }^{\circledR}$-associated 


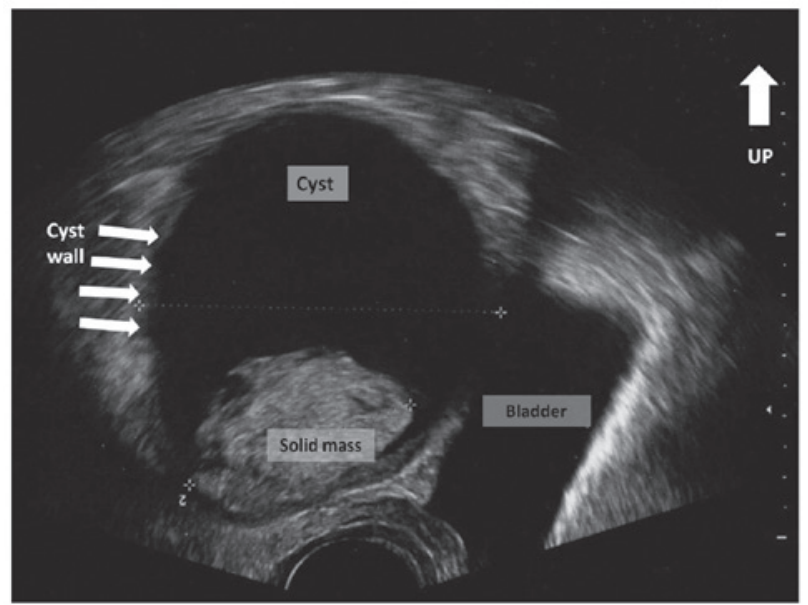

Figure 1. Transvaginal ultrasound revealed an $89-\mathrm{mm}$ cystic lesion, with a 37-mm hyperechoic area on its wall, located in the right perivesical space. White arrows indicate the wall of the cystic lesion.

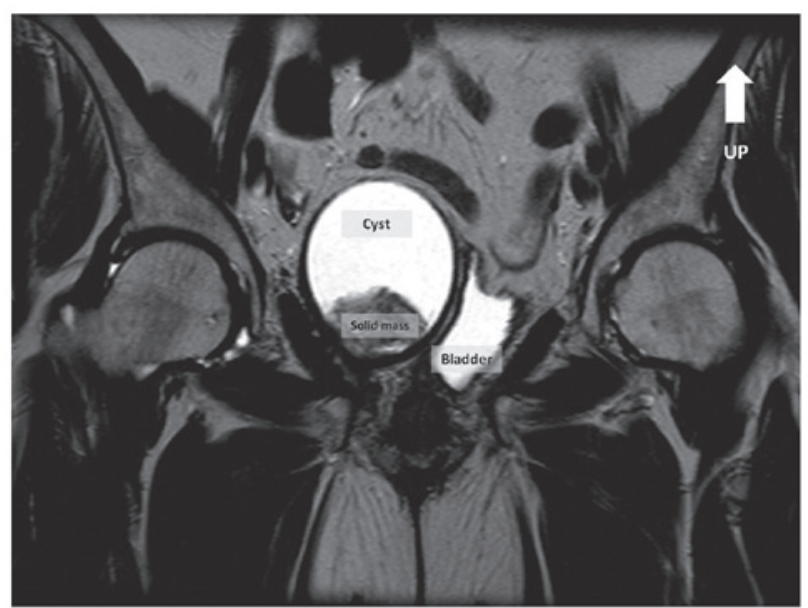

Figure 2. Magnetic resonance imaging confirmed the presence of a cystic lesion with a thick solid inner area.

abscess was established, and one month subsequent to surgery the irritative voiding symptoms experienced by the patient had completely ceased.

\section{Discussion}

Intraoperative use of adjuvant hemostatics has become a common practice in gynecological and other types of surgery (2). Surgicel ${ }^{\circledR}$ is frequently used for hemostasis in a number of surgical procedures (2). Absorption of Surgicel ${ }^{\circledR}$ commences within $24 \mathrm{~h}$ following surgery, and complete resorption typically occurs within 4-8 weeks (9). It is common for oxidized cellulose to appear as a mass during the immediate postoperative period, and this should not be confused with a postoperative abscess (9), tumor (10) or hematoma (11). Radiological features are nonspecific, and differential diagnosis may be particularly difficult, as the lesion may exhibit a tumor-like appearance (12).

The computed tomography (CT) features of Surgice ${ }^{\circledR}$-associated granuloma include focal or linear collections of mixed attenuation located in or near the operative site, as well as pockets of air and absence of contrast enhancement and air-fluid levels (9). Over time, these pockets of air are completely replaced by soft tissue, leading to the formation of a foreign body granuloma (9). This granuloma may clinically and radiologically resemble a neoplastic lesion, and may therefore be a diagnostic challenge (6).

MRI findings are nonspecific, although the presence of hypointense stripes inside a cystic-like cavity on T2 weighted images is considered to be a characteristic sign of Surgicel ${ }^{\circledR}$-associated granuloma (13). Despite the high accuracy of positron emission tomography (PET)/CT scanning, this method may produce false-positive results in cases of foreign body granuloma, possibly as a consequence of localized inflammation mimicking malignant tissue glucose uptake (14). Imperiale et al (8) reported the case of a patient with ovarian cancer where combined ${ }^{18} \mathrm{~F}$-fluorodeoxyglucose PET/CT suggested isolated cancer relapse. However, the lesion was surgically removed and demonstrated to be a foreign body granuloma (8).

The present case has been reported in order to alert surgeons to the risk of using and leaving in situ oxidized cellulose. Furthermore, accurate evaluation of the surgical history of the patient should always be performed prior to attempting surgery.

\section{References}

1. Achneck HE, Sileshi B, Jamiolkowski RM, Albala DM, Shapiro ML and Lawson JH: A comprehensive review of topical hemostatic agents: Efficacy and recommendations for use. Ann Surg 251: 217-228, 2010.

2. Hadi HI, Maw A and Hay DJ: A simple technique to control iatrogenic solid organ injury haemorrhage. Surgeon 2: 339-361, 2004.

3. Sabel M and Stummer W: The use of local agents: Surgicel and Surgifoam. Eur Spine J 13 (Suppl 1): S97-S101, 2004.

4. Rappaport W and Haynes K: The retained surgical sponge following intra-abdominal surgery. A continuing problem. Arch Surg 125: 405-407, 1990.

5. Buckley SC and Broome JC: A foreign body reaction to Surgicel(R) mimicking an abscess or tumour recurrence. Br J Neurosurg 9: 561-563, 1995.

6. Deger RB, LiVolsi VA and Noumoff JS: Foreign body reaction (gossypiboma) masking as recurrent ovarian cancer. Gynecol Oncol 56: 94-96, 1995.

7. Gao HW, Lin CK, Yu CP, Yu MS and Chen A: Oxidized cellulose (Surgicel) granuloma mimicking a primary ovarian tumor. Int J Gynecol Pathol 21: 422-423, 2002.

8. Imperiale L, Marchetti C, Salerno L, Iadarola R, Bracchi C, Vertechy L, di Francesco L, Musella A, Bevilacqua E, Pennesi P, et al: Nonabsorbable suture granuloma mimicking ovarian cancer recurrence at combined positron emission tomography/computed tomography evaluation: A case report. J Med Case Rep 8: 202, 2014.

9. Young ST, Paulson EK, McCann RL and Baker ME: Appearance of oxidized cellulose (Surgicel) on postoperative CT scans: Similarity to postoperative abscess. AJR Am J Roentgenol 160: 275-277, 1993.

10. Sandhu GS, Elexpuru-Camiruaga JA and Buckley S: Oxidized cellulose (Surgicel) granulomata mimicking tumour recurrence. Br J Neurosurg 10: 617-619, 1996.

11. van Gelderen F and Swinnen J: Appearance of oxidized cellulose (Surgicel) on abdominal radiographs. AJR Am J Roentgenol 167: 1593, 1996.

12. Kim SR, Baik HK and Park YW: Retained surgical sponge presenting as a pelvic tumor after 25 years. Int J Gynaecol Obstet 82: 223-225, 2003.

13. Oto A, Remer EM, O'Malley CM, Tkach JA and Gill IS: MR characteristics of oxidized cellulose (Surgicel). AJR Am J Roentgenol 172: 1481-1484, 1999.

14. Ghersin E, Keidar Z, Brook OR, Amendola MA and Engel A: A new pitfall on abdominal PET/CT: A retained surgical sponge. J Comput Assist Tomogr 28: 839-841, 2004. 